\title{
Using a co-created transdisciplinary approach to explore the complexity of air pollution in informal settlements
}

Sarah E. West (1D ${ }^{1 凶}$, Cressida J. Bowyer (D) ${ }^{2}$, William Apondo ${ }^{3}$, Patrick Büker ${ }^{4}$, Steve Cinderby (D) ${ }^{1}$,

Cindy M. Gray (1) 5, Matthew Hahn ${ }^{6}$, Fiona Lambe ${ }^{7}$, Miranda Loh ${ }^{8}$, Alexander Medcalf ${ }^{9}{ }^{9}$, Cassilde Muhoza ${ }^{3}$, Kanyiva Muindi ${ }^{10}$, Timothy Kamau Njoora ${ }^{11}$, Marsailidh M. Twigg (10 ${ }^{12}$, Charlotte Waelde ${ }^{13}$, Anna Walnycki ${ }^{14}$, Megan Wainwright (D) ${ }^{15}$, Jana Wendler ${ }^{16}$, Mike Wilson (i) ${ }^{17} \&$ Heather D. Price (iD ${ }^{18}$

We present novel co-created transdisciplinary research that uses arts and humanities methods to explore air pollution in an informal settlement (Mukuru) in Nairobi, Kenya. Air pollution is a well-documented major human health issue, but despite many air pollution reduction interventions designed to improve health, these are frequently ineffective. Often this is because they fail to account for local knowledge, cultural practices and priorities of the intended recipients. Designing solutions therefore requires in-depth exploration of relevant issues with stakeholders. Researchers worked collaboratively with local residents to develop a range of methods to explore understandings of air pollution including interviews, storytelling, participatory mapping and theatre. Together, we uncovered contrasting definitions of air pollution, differing perceptions of who was responsible for enacting solutions, and overall a view that air pollution cannot be seen in isolation from the other issues faced by settlement residents. The methods used also allowed us to communicate about the topic with a wide audience. While we acknowledge that this research approach is more time consuming than traditional approaches, we urge other researchers wishing to address multifactorial problems, such as air pollution to use a mixture of qualitative, participatory and creative methods to engage with a wide range of stakeholders to elicit new and unexpected understandings that may not otherwise emerge.

\footnotetext{
${ }^{1}$ Department of Environment and Geography, Stockholm Environment Institute, University of York, York, UK. ${ }^{2}$ University of Portsmouth, Portsmouth, UK. ${ }^{3}$ Stockholm Environment Institute, Nairobi, Kenya. ${ }^{4}$ Deutsche Gesellschaft für Internationale Zusammenarbeit (GIZ), Eschborn, Germany. ${ }^{5}$ University of Glasgow, Glasgow, UK. ${ }^{6}$ Independent theatre for development practitioner, London, UK. ${ }^{7}$ Stockholm Environment Institute, Stockholm, Sweden. ${ }^{8}$ Institute of Occupational Medicine, Brimington, UK. ${ }^{9}$ University of York, York, UK. ${ }^{10}$ African Population and Health Research Center, Nairobi, Kenya. ${ }^{11}$ Kenyatta University, Nairobi, Kenya. ${ }^{12}$ UK Centre for Ecology and Hydrology, Lancaster, UK. ${ }^{13}$ Coventry University, Coventry, UK. ${ }^{14}$ International Institute for Environment and Development, London, UK. ${ }^{15}$ Durham University, Durham, UK. ${ }^{16}$ Playfuel Games CIC, Manchester, UK. ${ }^{17}$ Loughborough University, Loughborough, UK. ${ }^{18}$ University of Stirling, Stirling, UK. ${ }^{凶}$ email: sarah.west@york.ac.uk
} 


\section{Introduction}

ackling air pollution is essential for achieving the UN Sustainable Development Goals (SDGs) including Goal 3: Good Health and Wellbeing, Goal 7: Affordable and Clean Energy and Goal 11: Sustainable Cities and Communities. Air pollution is the leading environmental risk factor (after sanitation) for human health, in particular for respiratory and cardiovascular diseases (Hoek et al., 2013; Ritchie and Roser, 2017; WHO, 2018a) as well as preterm births (DeFranco et al., 2016). The Global Burden of Disease 2015 study (Forouzanfar et al., 2016) estimated that $\mathrm{PM}_{2.5}$ (fine particulate matter) alone was associated with 920,000 premature deaths annually in Africa. Air pollution-related health effects also negatively impact the resilience, productivity and well-being of people, putting extra burden on national economies due to health costs and loss of productivity (e.g. He et al., 2019). Air pollution has also been linked to increased severity of outcomes during the Covid-19 pandemic (Conticini et al., 2020; Wu et al., 2020). Despite scientific knowledge from the research community about the impacts of air pollution on health, and various global, regional and local campaigns and interventions, this problem still persists.

Outdoor and indoor particulate matter concentrations are particularly high in Africa's informal settlements, which are often located near roads and industry, are characterised by housing with limited ventilation and are home to people that predominantly rely on solid fuels for cooking (Bruce et al., 2000; Shupler et al., 2020). Nairobi, like many cities in Africa, has a high percentage of residents living in informal settlements (Goodfellow and Taylor, 2009), where high levels of $\mathrm{PM}_{2.5}$ have been recorded (Egondi et al., 2016; Muindi et al., 2016; deSouza, 2020). Efforts designed to reduce air pollution exposure have had mixed results. There is some evidence that interventions to increase the use of cleaner cookstoves, for example, have not been successful in terms of health outcomes (e.g. Mobarak et al., 2012; Mortimer et al., 2017; McCarron et al., 2020; Rouse, 2000). There are various reasons for the lack of positive health effects, including the fact that air pollution is often not visible and that noncommunicable diseases linked to air pollution may not be as high on people's 'concern agenda' as challenges linked to income and livelihoods (e.g. Muindi et al., 2014). Evidence suggests that top-down interventions often fail and therefore people should be put at the centre of developing the solutions (Rouse, 2000).

In seeking to address the shortcomings of traditional research interventions, this study started from the premise that solutions need to consider the priorities of the local population and be practical, ideally offer co-benefits (i.e. having positive effects in other areas), affordable, and coherent with local social and cultural understandings, practices and norms. The design of the study drew on research that emphasises the need for an inter- or transdisciplinary approach to solutions (Cook et al., 2014; Ezzati and Kammen, 2002; Marshall et al., 2018) incorporating local stakeholders' knowledge (Nantanda et al., 2019). Creative methods have been shown to be able to play an important role in bringing diverse stakeholders together to identify solutions to complex issues (Cinderby et al., 2021). Conventional research and planning methods which rely on verbal or written responses can be inadequate for capturing people's perceptions, experiences and fears which can be difficult to verbalise (Brooks et al., 2020). Marginalised groups are often not given the chance to voice their experiences of their environment due to multiple factors of mainstream disengagement, including social, linguistic, and spatial (Finney and Rishbeth, 2006; Olufemi and Reeves, 2004). Engaging creatively with communities by using playful approaches has proved useful for understanding social experience and facilitating collaborative effort (Gauntlett, 2007), and empowering project participants (Jiang et al., 2020).
The current research extends these arguments by exploring the strategies used on the AIR Network project. The project draws upon thinking from both the emerging fields of medical and health humanities (Bates et al., 2015; Bleakley, 2019; Cole et al., 2014; Crawford et al., 2015), as well as transdisciplinary, integrative and co-design approaches to research and knowledge production.

Transdisciplinarity can be defined as "a reflexive, integrative, method-driven scientific principle aiming at the solution or transition of societal problems and concurrently of related scientific problems by differentiating and integrating knowledge from various scientific and societal bodies of knowledge" (Lang et al., 2012, pp. 26-27). This integrating of knowledge is important for incorporating diverse perspectives, addressing power differentials between knowledge systems and building connections and relationships between academic and community members (Chilisa, 2017). Transdisciplinary co-production is where research activities are conducted outside of scientific institutions such as universities, and the actors (both researchers and stakeholders) jointly own, initiate, manage and carry out the research process, and is an innovative way to reach relevant societal actors beyond the ivory towers of academia (Lang et al., 2017). It aims towards the co-creation of new knowledge and insights through a mutual recognition of the equal value of different knowledge systems and frameworks, and an appreciation of how the interplay of those systems can create new ways of thinking and understanding. This can lead to the production of useful and relevant knowledge, and in situ, context-based problem solving (Polk, 2015). This is particularly important where problems are challenging, complex and intractable, as is the case with air pollution (Holgate and Stokes-Lampard, 2017).

Previous studies in informal settlements in Nairobi have found that understanding perceptions of, and attitudes towards, air pollution are critical for reducing exposure as they can influence the response to interventions aimed at encouraging behaviour change (Muindi et al., 2014). Some studies have used citizen science and other approaches, which allowed exploration of the issues alongside monitoring of air pollution. West et al. (2020) worked with six residents to use portable low-cost sensors to explore their exposure to particulate matter and found significant variation both temporally and spatially in the settlement. Twigg et al. (2017) carried out a combination of low-cost static air quality monitoring and personal exposure monitoring working closely with community champions to gain knowledge about the personal and community exposure of air pollution within Mukuru. Dianati et al. (2019) investigated the issue of household air pollution using participatory stakeholder workshops. The use of participatory approaches in air pollution studies has been advocated in a study undertaken by Ngo et al. (2017) in Nairobi. This study was different in that, for the first time, it placed arts and humanities methods at the centre of the exploration of perceptions of air pollution. In so doing it pushed the boundaries between disciplines, between research and action, and between experts by education and experts by experience. Our aim was to develop and use a novel transdisciplinary co-creation research approach to build an understanding of community experiences of air pollution in an informal settlement in Nairobi.

\section{Methods}

Study location. Nairobi, Kenya, is a city with a population of 4.4 million (KNBS, 2020), with an estimated $60-70 \%$ of people living in informal settlements (Beguy et al., 2015). Mukuru Kwa Njenga, Mukuru Kwa Reuben and Viwandani (collectively referred to here as Mukuru) are three neighbouring informal settlements 


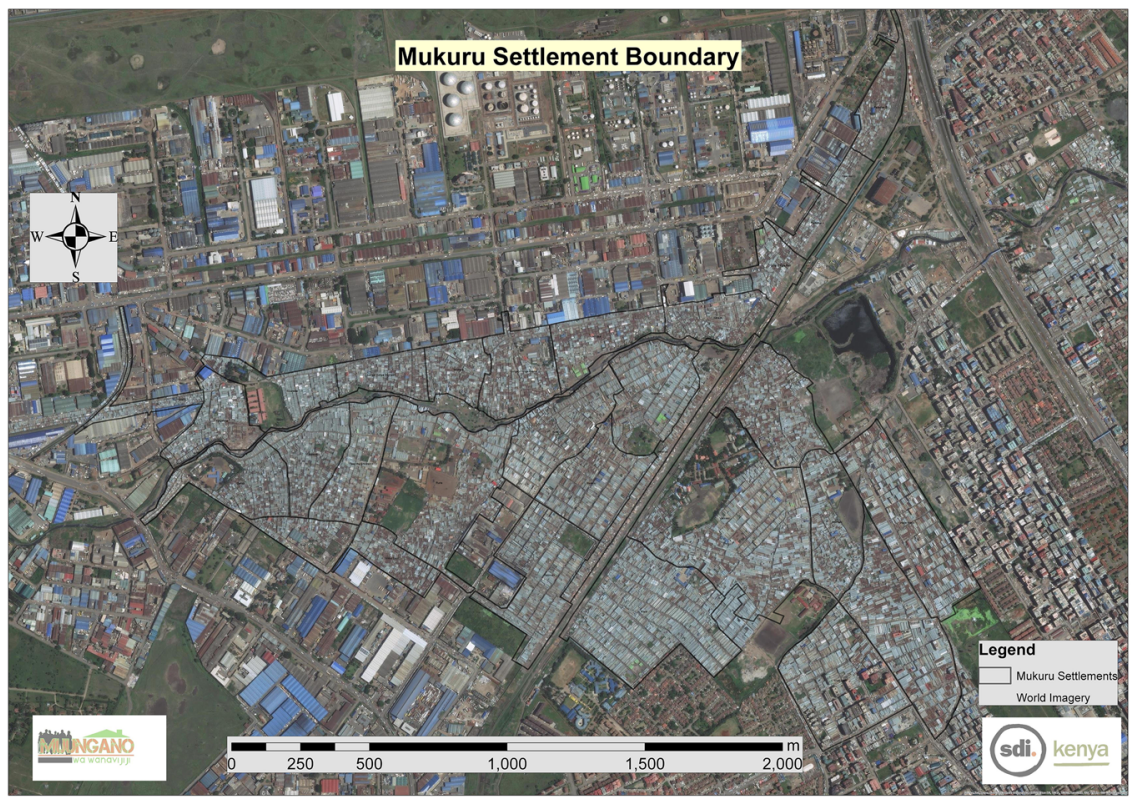

Fig. 1 Mukuru informal settlement boundaries. Map provided by Mukuru Youth Initiative and Muungano wa Wanavijiji, Slum Dwellers International.

located in the Embakasi South and Makadara sub-counties of Nairobi (see Fig. 1). The settlements are located on a mixture of privately and publicly owned land. Around 100,000 households inhabit this area, living in small overcrowded shacks constructed of sheet metal, with concrete or earth floors. Provision of services is extremely limited (Dianati et al., 2019). Sanitation is inadequate, garbage disposal is poorly managed, open drainage channels are ubiquitous and access to electricity and water supplies are subject to a poverty penalty, so residents pay more for a lower quality service than elsewhere in the city (Corburn et al., 2017). The multiple burdens the community endure manifest themselves in significant health problems, including high levels of respiratory disease (Gulis et al., 2004) and cardiovascular diseases which are important causes of death locally (Mberu et al., 2015). This is mirrored in informal settlements around the world, as their location (often close to sources of air pollution), crowded housing and high reliance on inefficient solid fuels for cooking (WHO, 2018b) means that residents are at high risk of being affected by infectious and non-communicable respiratory diseases, many of which are linked to air pollution exposure (Checkley et al., 2016).

Study approach. Co-creation and creative methods were at the heart of the project. Co-creation of interventions requires a close and trustful partnership of researchers and community members (Greenhalgh et al., 2016). Creative methods have previously been found to empower people to identify their own solutions to problems (Cinderby et al., 2021). They can open up unique avenues for discovery (Biggs and Buchler, 2008) and participatory arts-based methods are able to utilise culturally relevant practices to assimilate and analyse data and foster ownership of research findings (Coemans and Hannes, 2017). To achieve the project aims, we therefore used multiple qualitative, participatory and creative methods to explore perceptions and experiences of air pollution.

A first step brought researchers and practitioners from Kenya, the UK and Sweden together with informal settlement community representatives in Nairobi. The AIR Network had contributions from national (Kenyan) and international academics from the arts and humanities, social and natural sciences, people who live and work in the informal settlements and local policymakers, coming together to discuss air pollution related issues, raise awareness and consider potential solutions. The team held a 4-day inception workshop in Nairobi in January 2018, which was planned and facilitated by researchers in Kenya and the UK, and included activities to develop a shared understanding of air pollution from differing perspectives. A cross section of Mukuru residents were invited to attend the 4-day workshop. They represented a mixture of community champions from previous research projects (for example, West et al., 2020), and artists, school teachers and community health workers who had previously worked with Muungano, a community organisation that is affiliated to Slum Dwellers International (Muungano wa Wanavijiii, 2018). To overcome the often rigid one-directional format of consultation workshops, from the start of the workshop Mukuru residents were encouraged to become co-researchers, for example, helping create project 'ground rules' and a 'contract for interdisciplinary working'. Early in the workshop they led a tour through the settlement to establish a common understanding of the environmental challenges residents face, and then codeveloped four mini-projects around the topic of air pollution. These mini-projects were time-bound activities conducted by community members and researchers to build collaboration whilst gaining an understanding of the air pollution situation. By the end of the workshop, a working group for each mini-project was established to explore air pollution using a variety of qualitative, participatory and creative methods. These projects focused on four inter-linked topics identified by community members: raising awareness, taking action, engaging with industry and prioritising policies (see Fig. 2). Each project had elements of both data collection and dissemination.

Data collection and analysis. The co-designed mini-projects used a mixture of methods which included qualitative interviews, storytelling, participatory mapping, theatre, music and playful activities to explore air pollution. At the end of the project, representatives from each mini-project came together to discuss key emerging themes.

Interviews. Five female community representatives conducted semi-structured qualitative interviews with nine stakeholders in August 2019. Interviewers received training in narrative-style interview techniques (Mattingly and Garro, 2000) and in 


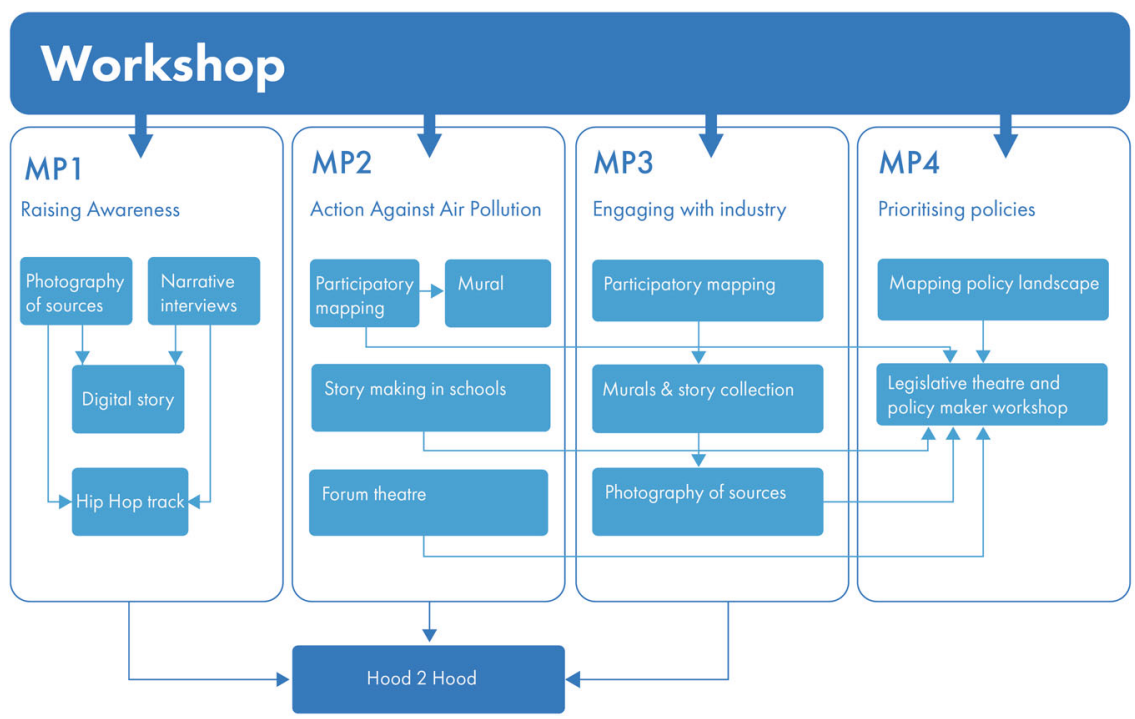

Fig. 2 Visualisation of the activities of the project. Project activities within the four mini-projects (MP) are shown in blue boxes, with arrows showing how they related to each other.

procedures for obtaining informed consent. Interview guides and consent forms were provided in English and Swahili, and interviews were conducted in either of these or Sheng. Purposive sampling was chosen to maximise variation in perspectives. The final sample (three men, six women) included a politician, a doctor, a researcher, a teacher, a community health visitor, a cook, a community volunteer, a factory worker, and a car washer. The doctor and researcher lived in Nairobi but not in Mukuru; the other interviewees lived locally. Interview questions (see Supplementary Information) allowed interviewees to tell their own stories in line with narrative theory which asserts that human beings have an innate capacity to organise their world through narratives (Bruner, 1990). Open-ended questions were framed to elicit explanatory models of air pollution, including the sources, effects of and solutions to air pollution. Though explanatory models theory was originally developed in the context of doctor-patient perspectives on illness (Kleinman, 1987), it has been adapted to explore other topics such as air pollution where divergent views exist (Harper, 2004). Swahili and Sheng interviews were transcribed into English and then imported into NVivo and each interview was listened to or read multiple times by a single researcher. Each mention of a source, effect or solution to air pollution was noted in a separate Mind Map (QSR NVivo 12 version 12.6). Mind Maps branched out from the central topic (source, effect, solution) into two layers of responses. The first layer included all the sources, effects and solutions to air pollution proposed by the participants. The second layer included contradictory or opposing views to specific responses presented in the first layer.

Storytelling. Storytelling as a means of communication is deeply rooted in African history and religion, is a major form of informal education and is used for conveying important messages (Gathogo, 2007). It enables us to communicate both concrete and abstract concepts, and to explore, test and negotiate our relationship with the social and natural environments in which we act, including the formation of identity and relationships between each other and our environment. It is one of the most important foundations of us as social beings (Bauman, 1986). Storytelling is the glue of human social life (Gottschall, 2012), and can create a deep sense of friendship and of community, as experiences are shared and injustices discussed (Gathogo, 2007). The stories we tell convey our identities, histories, cultures and values. Our status as "homo narrans" (Gold, 2002) is critical to our individual and collective survival, giving us the ability to address our many challenges.

Storytelling was used in multiple ways (see Fig. 2) to engage Mukuru residents in thinking about air pollution, interrogating and identifying the cultural and socio-economic drivers that were the underlying causes of poor air quality, and engaging the wider community in discussions around co-producing strategies and solutions. Providing non-written opportunities to contribute was important as these forms of expression can reveal more about people's experiences (Lindhout et al., 2020).

Digital storytelling enabled people to tell, capture and disseminate their personal stories through a combination of voice, text and still image. Digital stories are typically $2-3 \mathrm{~min}$ in length and shared through community-based screening events, exhibitions and via web-based platforms (see Hartley and McWilliam, 2009; Lambert, 2002). The creation of a digital story is a form of 'slow' storytelling, focusing on storytelling as a reflective process (Wilson, 2021). Community members made digital stories by taking photographs around Mukuru which, when stitched together and combined with their voiceover, told their story of air pollution. In addition, trained community researchers facilitated school children to create drawn and/or written stories of their experiences of air pollution. Finally, community members spent a week in September 2018 developing two stories about experiences of air pollution and poor lung health, which they performed (with the forum theatre, see below) at a market, community centre and football ground in Mukuru.

Participatory mapping. Participatory mapping is a "bottom-up" methodology which aims to capture, and make visible, the relationship between people and the spaces in which they inhabit (Brown and Kyttä, 2018; Cochrane and Corbett, 2018). Maps may capture both tangible information (e.g. roads) and intangible information (e.g. feelings). Participatory mapping has been used extensively over the past three decades as a research technique in multiple academic fields including land use planning, natural resource management and disaster risk reduction (Brown et al., 2018; Cadag and Gaillard, 2012). It has been used to explore perceptions of air quality in some UK cities (Cinderby et al., 2008; Cinderby and Forrester, 2005). In this project, the 
aim of participatory mapping was to explore what and where the key air pollution sources were in Mukuru, and to identify community-led solutions to the problem. Researchers worked with artists from the local Wajukuu Arts organisation (https:// wajukuuarts.wordpress.com/) to develop the mapping methodology (used in mini-projects 2 and 3). Artists created a large map for each of the areas in Mukuru (Kwa Reuben, Kwa Njenga, Viwandani) showing points of interest that they felt would be meaningful to Mukuru residents. Once the maps were completed, each map was taken to its respective area and passers-by were asked to attach stickers to show where they experienced air pollution. This on-street, rapid mapping approach has successfully been used in other contexts (see Cinderby, 2010). More than 500 residents were asked what the source of air pollution at that location was, how it could be reduced and by whom, and some basic socio-demographic information.

Theatre. There are various typologies of participation in theatre. This project relied on 'interactive participation' to create space for a joint problem analysis, production of action plans and local residents taking ownership of decisions and ensuring action takes place (Prentki and Preston, 2009). During the initial workshop in January 2018, the team had a chance to try out various forms of theatre as possible methods for mini-projects. Forum and legislative theatre were chosen to target two discrete audiences. Forum theatre aims to encourage more positive choices in individual behaviour, and the audience are community members who share the oppressions that have been displayed (Boal, 2008). In legislative theatre, the audience are not necessarily members of the community, and may not have experienced the issues displayed on stage. Instead, this audience is specifically targeted because they have the power to make positive systemic changes to alleviate the oppressions displayed. In both forms of theatre, the audience are 'spect-actors' (that is, both spectators and actors; Boal, 2008) and can propose and test a solution to the play by joining the scene. The other actors push back against the changes proposed by the spect-actors to replicate the real-world difficulties of behaviour change (forum theatre) and systemic change (legislative theatre).

Theatre pieces were developed over a week in September 2018. The first phase facilitated cohesion of the community members involved in creating the theatre pieces, group work to identify the focal problem, and collective and artistic creation of the play including storyline, script and acting (Salvador, 2014). As part of this, individuals were asked to tell a story about how air pollution had affected them. These rich and detailed stories provided a wealth of source material for the group to develop several storylines for both forum and legislative theatre pieces.

The forum theatre pieces were presented in key community spaces around Mukuru including at a market, a community centre and a football ground. Suggestions were given by the audience about how to resolve the problem and spect-actors acted out their proposals as part of the theatre. The legislative theatre pieces were performed before an audience that included policy makers in a position to affect change in the community, and, as with the forum theatre pieces, spect-actors made suggestions to improve the outcome of the plays, which they acted out. Directly following the legislative theatre performances, a workshop was facilitated with $\sim 40$ participants, including the actors, spect-actors and other audience members, including a range of policy makers from local-level to county-level covering different relevant departments including Environmental Protection, Health, Waste Management and Urban Planning. The purpose of the workshop was to discuss the proposals raised in the legislative theatre performances, as well as to generate additional suggestions for addressing the issues presented and to reach a collective agreement about the actions needed.

Music. Music can be a powerful tool in participatory research studies to engage particular demographics (Gitonga and Delport, 2015) and for addressing complex social and political issues (Sibanda, 2004), including environmental issues (Publicover et al., 2018). During the project development phase, music was identified as an important tool for raising awareness and engaging the community. The community researchers included several talented musicians and filmmakers who composed original musical arrangements for the AIR Network, with accompanying music videos. The lyrics (see Supplementary Information) were written in response to the community views expressed at the January workshop and during mapping exercises, storytelling and theatre activities. One of the key musical outputs, the song 'Mazingira' by the Mukuru Kingz, has been played on national radio and television stations with an estimated reach of three million people, and Mukuru Kingz talked about the AIR Network on local TV and radio. The song was performed live at the AIR Network Hood2Hood festival (see the section "Hood2Hood festival") and at the World Environment Day concert in Nairobi. As of August 2021, the video had 1840 views on YouTube, with 92 likes and 16 positive comments, ranging from appreciation for the track to wider reflections on the need for a healthy nation.

Hood2Hood festival. At the inception workshop, community members suggested a celebration event to share the project outputs, and to talk about air pollution with the wider Mukuru community. Festivals are common in Mukuru for awareness raising, bringing together dance competitions, local music stars and MCs with informative messaging, and attract a large crowd ranging from young children to adults. Led by community members with a background in community event organisation, the AIR Network held a one day Hood2Hood neighbourhood festival in September 2018 at a local football ground. A stage, managed by experienced MCs, presented AIR Network outputs (stories, theatre and music) alongside local music acts. Around the area, activities such as face painting and mural creation, led by local artists, engaged children and youth in air pollution issues.

Playful activities were used at the Hood2Hood to engage a cross-section of Mukuru residents. Play is a form of participation which makes players aware of their social agency (Henricks, 2015). It draws on the power of materials to incite enjoyable interactions (Langham, 2017). A series of interactive boards were designed with questions for the community including (1) What is the main cause of air pollution in Mukuru? and (2) Whose responsibility is it to reduce air pollution? The boards had a selection of answers, informed by findings from other methods, both written and drawn, with small containers made from recycled plastic bottles underneath (see Fig. 3). Boards were positioned at one of the entrances to the football ground where they attracted great attention, and many people enjoyed dropping their three beans into the bottles. The visual impact of the boards developed throughout the day and facilitated conversations around understandings of air pollution.

Attribution. Care was taken to ensure that where possible and appropriate, the authors and performers of the creative works were given due credit for their input. Such attribution, as required by the laws of copyright and performers rights, not only respects creative input (including where recorded copies are made available), but also helps the author(s) to take ownership of the creative work, and to resist any attempt to use their creative outputs to co-opt communities to official agendas. 


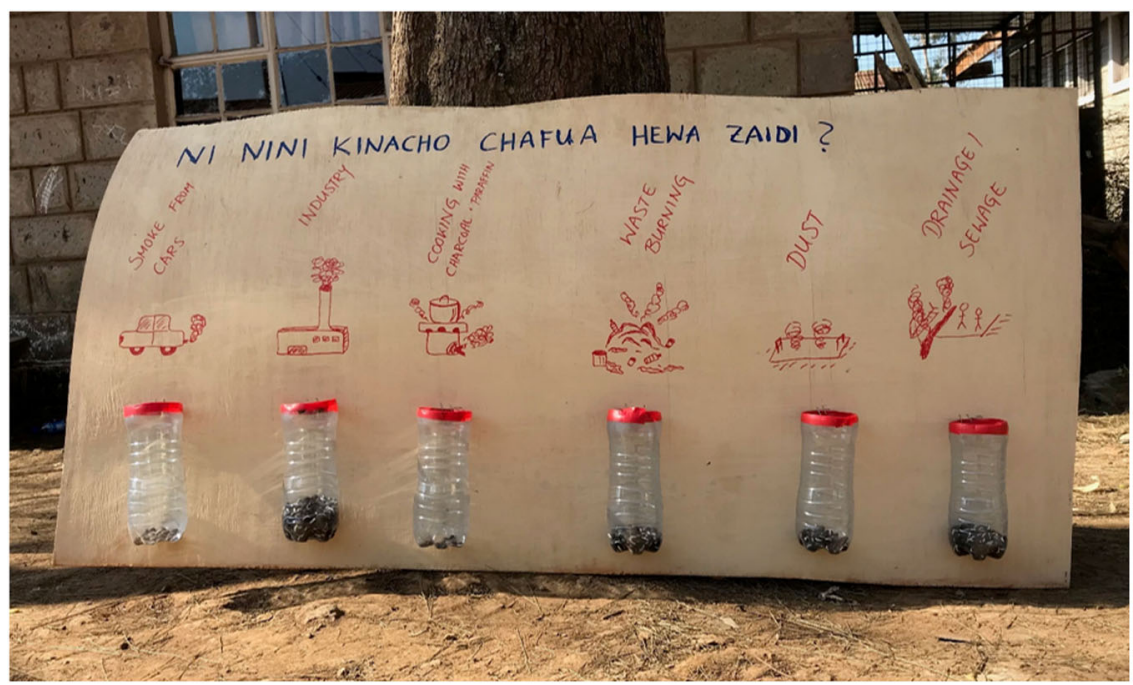

Fig. 3 Photograph showing the results from a playful activity exploring air pollution sources with Mukuru residents at the Hood2Hood festival. Residents were asked to put counters into the 'top 3' sources of air pollution in Mukuru. The title translates as 'What pollutes the air most?". Initial options included were designed in partnership with community representatives.

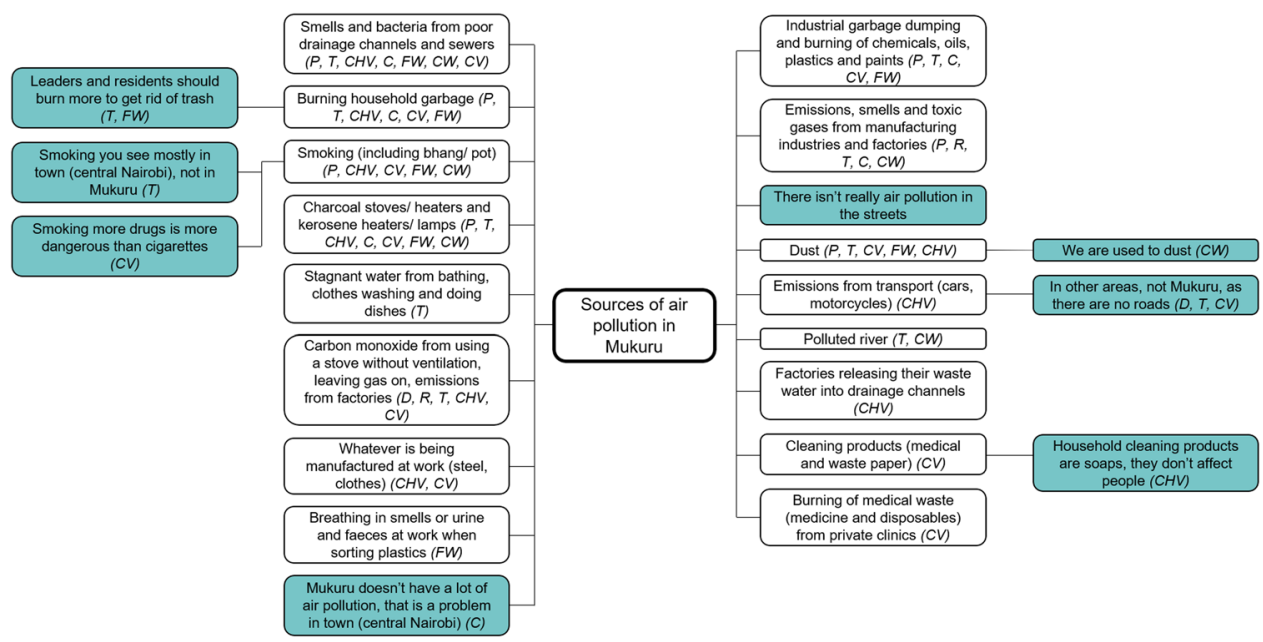

Fig. 4 Range of responses to questions asked during interviews with nine residents about sources of air pollution in Mukuru. Blue boxes represent contrary views either generally (e.g. no air pollution problem) or contrary to a source mentioned by another participant. P politician, D doctor, R researcher, $\mathrm{T}$ teacher, CHV community health visitor, C cook, CV community volunteer, FW factory worker, CW car washer.

\section{Results and discussion}

From this range of methods we have, firstly, gained a more complex and nuanced understanding of how air pollution is perceived and understood in Mukuru. Second, the project created new spaces and forums for dialogue and critical reflection on the topic of air pollution in the community.

Understanding perceptions of air pollution. Our research highlighted many sources of air pollution across Mukuru and differing understandings among the community of what constitutes pollution. Sources of air pollution noted in the interviews were poor drainage, stoves for cooking and heating, burning household waste, smoking, dust and industrial emissions (Fig. 4). Several contrary views emerged, for example while burning household waste was cited by many as a common source of air pollution, others felt that more waste burning was required to clean up the local environment.
In the interactive boards at the Hood2Hood (see Fig. 3), of 701 counters placed by around 230 residents, the most common sources of air pollution highlighted were industry $(45 \%$ of counters), drainage (24\%) and waste burning (17\%). Dust (8\%), smoke from cars $(4 \%)$ and cooking $(2 \%)$ were considered less important sources of air pollution in Mukuru. The lack of counters in 'cooking' was particularly interesting, as this is known to be an important source of indoor pollution in this and other informal settlements in Nairobi (Egondi et al., 2016; Muindi et al., 2014; West et al., 2020) and elsewhere. This finding was replicated in the mapping exercise, which highlighted that residents perceived there to be hotspots of air pollution in a variety of locations across the settlement, including along the river, near the rubbish dump, and from particular factories (see example map in Fig. 5), but there were few dots placed on homes. People may not identify their activities at home as air pollution sources, as often air pollution is identified as an outdoor issue, and 'stereotypical' sources tend to be industry and cars. Other studies have found 


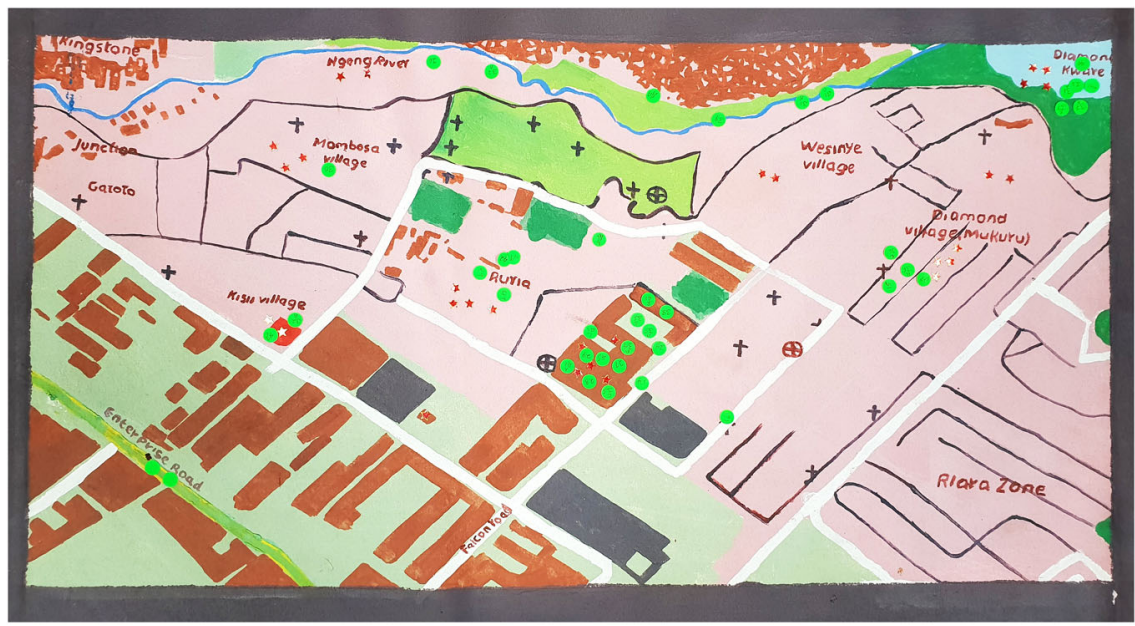

Fig. 5 Map of part of Mukuru drawn by community artists showing areas where local residents experience high air pollution (green dots).

that individuals rate their vulnerability to air pollution as low, despite facing high levels of household air pollution (Avis et al., 2018; Avis, 2018). This may reflect a household level form of the 'neighbourhood halo effect' reported in previous studies where individuals are less likely to perceive air pollution as a problem locally (Bickerstaff and Walker, 2001; Rankin, 1969).

In contrast, in the children's stories, smoke from cookstoves was the most prominent form of air pollution (see example in Fig. 6), followed by road vehicles and people smoking. This may reflect the different participants' respective daily experiences, i.e. children are likely to spend more time in the home experiencing the smell of smoke during cooking compared to, for example, adult males (e.g. Mahalanabis et al., 2002). It may also be due to the different locations where the activities were undertaken, i.e. indoors for the children's stories and outdoors for the participatory mapping and the playful activity at the Hood2Hood festival, cooking smoke is 'out of sight, out of mind' when outside. Occupational exposure to air pollution was identified only through the legislative theatre, where exposure to air pollution in a factory was making workers sick.

Place and context have long been recognised as influencing the focus of discussions and findings (Chambers, 1994), for example, perceptions about air quality are shaped by local context and lived experiences of communities (Bickerstaff and Walker, 2001). More recently the value of holding discussions in the places to which they relate has been adopted in various methodological innovations including on-street mapping (Cinderby, 2010); transect walk narratives (Jones and Evans, 2012) and place making activities (Jones and Evans, 2011). In one of the digital stories created by AIR Network members (see Fig. 7 and the video in Supplementary Information), photographs taken by Dennis Waweru towards the end of the project highlighted cooking and lighting as two of the key sources of air pollution in Mukuru, in addition to local industries, the polluted river (as result of poor solid waste management) and the burning of waste, including medical waste. The wide variety of both indoor and outdoor air pollution sources highlighted in the story may be due to the fact that Dennis participated throughout the AIR Network, attended some of the interviews in order to photograph sources of air pollution mentioned by interviewees, and therefore drew on their narratives to create his story. There was other evidence of knowledge change through the project: "I've learnt about how air pollution happens from different sources...you are burning garbage and making it easy to dispose, but you are affecting a lot of people that are surrounding you including yourself which we don't know but now we know" (female community

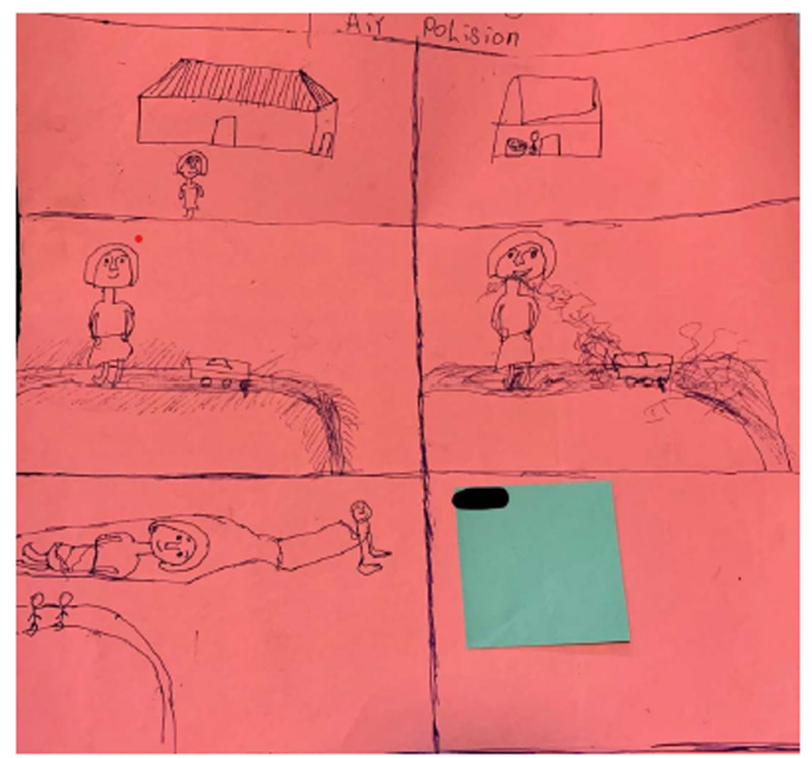

Fig. 6 Example of a picture drawn by a child attending school in Mukuru when asked to draw a story depicting their experiences of air pollution.

researcher), and "...not only is air pollution outside but it is also inside" (male community researcher). In a previous study in Mukuru (West et al., 2020), there was also evidence of a change in knowledge of air pollution by community research assistants during the project.

For residents of Mukuru, air pollutants were things that could be experienced; smelt (e.g. smelling burning trash at dumping sites or sewage smells), seen (e.g. seeing smoke coming from cooking fires) and heard (e.g. hearing metalworking industries in action). One of the interview participants stated: "air pollution is what surrounds us" and one of the community researchers stated "...air pollution is everywhere". In anthropologist Tim Ingold's conceptualisation (Ingold, 2007), humans occupy both the earth and the sky, and the air we breathe and move in is a constant intermingling of earth and sky; while Sumartojo and Pink (2018) refer to 'atmospheres' as the spaces in which we inhabit. These conceptualisations work particularly well in Mukuru where the air is filled with all sorts of smells, dusts, chemicals and smoke coming from below (e.g. blocked drains), above (e.g. factory chimneys), and between (e.g. smoke from a neighbour's stove drifting across and through your windows). Perceptions of risk 


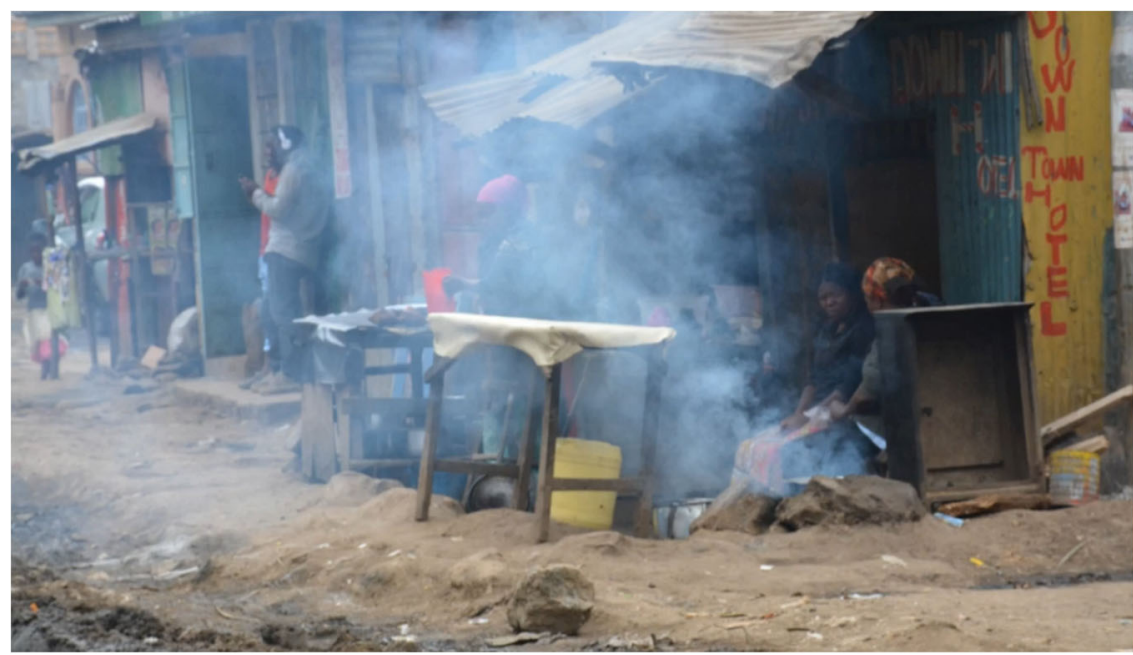

Fig. 7 Still from Dennis Waweru's digital story exploring air pollution in Mukuru. The full digital story is available in Supplementary Information.

are shaped by people's everyday social and cultural experiences, and in particular through the senses (Bickerstaff, 2004; Bickerstaff and Walker, 2001; Pink, 2015; Sumartojo and Pink, 2018), and many community-driven air quality monitoring studies result from concerns based on sensory perceptions (Commodore et al., 2017). In Mukuru, the exception to this sensory understanding of what constitutes air pollution was the pollutant carbon monoxide, which causes acute symptoms and even death. Carbon monoxide was mentioned in the interviews by five participants and was the focus of a forum theatre piece but is a scentless and invisible gas. The frequent mention of this pollutant could be due to the common public information broadcasts on radio and television warning of the risks of carbon monoxide poisoning, and the acute nature of the symptoms.

Some of those interviewed thought that air pollution was less of a problem in Mukuru and more of a problem 'in town' (i.e. in Nairobi city centre), where traffic congestion is a major issue. This may be an example of the "neighbourhood halo" effect, where people's perceptions of their local environment are more favourable than further afield (Bickerstaff and Walker, 2001). It may also be that air pollution is so embedded in people's daily lives in Mukuru, that it goes unnoticed (Muindi et al., 2014). This is supported by the fact that during the forum theatre, several Mukuru residents commented that they were beginning to see that they had 'normalised the abnormal' in their daily lives.

Academic research has traditionally prioritised European/ Western knowledge at the expense of indigenous and local knowledge (Chilisa, 2017). However, indigenous and local knowledge is a vital part of the design of any strategies to accelerate progress towards meeting the SDGs. Our findings highlighted that residents' definitions or framings of air pollution are vital, as important aspects of the problem will otherwise be missed. The key example of this identified here is the sewage smells coming from the drainage channels that cut across Mukuru as identified through the participatory mapping, interviews and the playful activities at the Hood2Hood festival. Previous research in the settlement (Muindi et al., 2014; West et al., 2020) also found that pungent drainage channels containing a variety of solid waste were frequently cited by people as major sources of air pollution. In Muindi et al. (2014) this perception was described as "flawed" knowledge and understanding. However they are a source of ammonia (Twigg et al., 2017; West et al., 2020), which contributes to the production of $\mathrm{PM}_{2.5}$ (Giannakis et al., 2019). 'Bad smells' should not be discounted as pollution, given that they are caused by chemical emissions, and negative perceptions of the environment impacts people's sense of well-being. By allowing community members to express their own knowledge, through song, stories and theatre, we reduced the risk of the views of privileged researchers excluding the views of the community about the issue and their thoughts on solutions (Marshall et al., 2018).

\section{Creating space for dialogue and critical reflection about solutions}

Community-led solutions to air pollution. Through our activities we were able to engage audiences (including youth) not usually involved in research, capturing their ideas about the potential solutions to air pollution. Solutions derived from our activities are shown in Fig. 8.

Our methods uncovered divergent perspectives on potential solutions to Mukuru's air pollution. There were those that focused on individual action (shown in green in Fig. 8), such as residents maintaining sanitation around their homes, burning garbage further away from where people live, and reporting air pollution problems to the chief. Others focused on structure owners (landlords), since a high proportion of residents in Mukuru rent their homes (Gulyani et al., 2018). Some respondents felt structure owners should support civic action, build homes with windows, and enforce tenants' obligations, for example around using stoves and turning them out quickly after use. Macro-level solutions such as economic empowerment, government monitoring, engagement with stakeholders and civic action were commonly mentioned, especially by the doctor and researcher interviewees. There were also contrary views (for example, from the car washer interviewee) that could suggest that residents whose occupation is not directly linked to civic action (such as health workers) may feel more disempowered to effect change, whether it be reducing emissions, intervening with neighbours' practices, or demonstrating.

Participatory mapping generated geo-located solutions which highlighted where implementation was needed (see Fig. 5). Most of the proposed solutions addressed outdoor sources of air pollution and relied on changes being made by those in positions of power. Examples included improved regulation of industries by the National Environment Management Authority (NEMA), educating the community on waste disposal, providing more toilets, tarmacing dusty roads, production of maps showing the location of waste disposal sites, and industries raising the height 


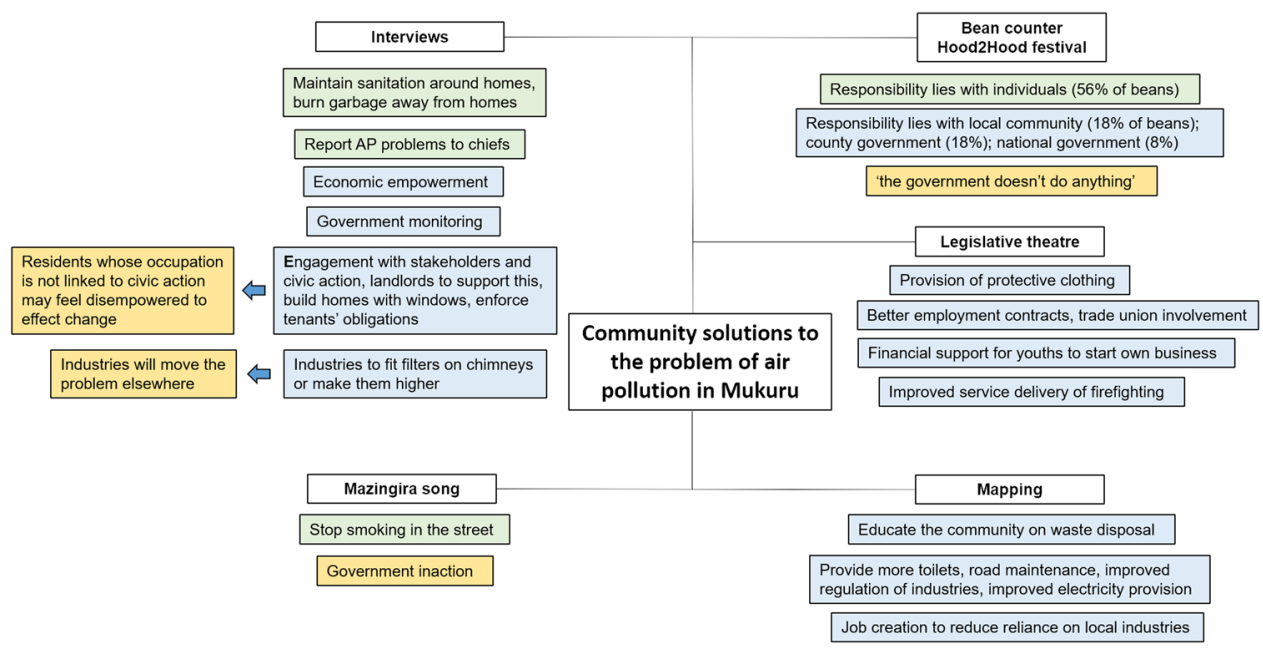

Fig. 8 Community solutions to the problem of air pollution in Mukuru, showing the method from which they were derived. Green boxes represent individual action. Blue boxes represent solutions requiring change at administrative or policy level. Orange boxes represent barriers to action.

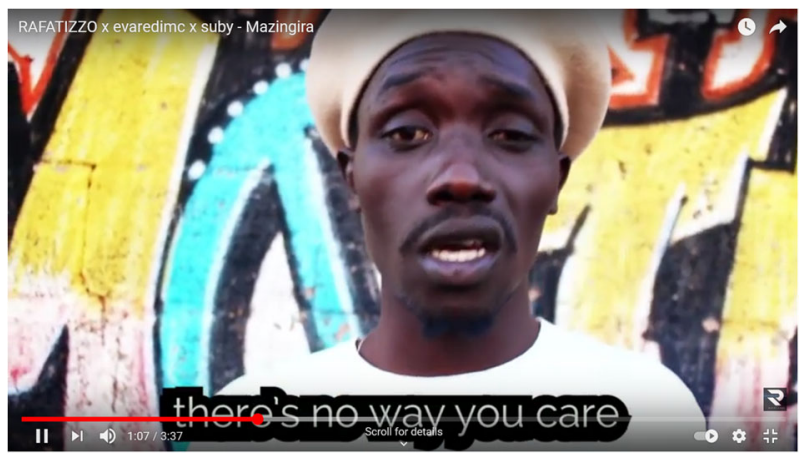

Fig. 9 Still from the music video for 'Mazingira' by Mukuru Kings, showing image of Rafatizzo. Lyrics and music video can be found in Supplementary Information.

of their chimneys. Some of these actions could be implemented quickly and easily, whilst others would require larger changes, and in the case of the chimney height, would just move the problem elsewhere. In contrast, at the Hood2Hood, the bean counter exercise showed the majority thought individuals were responsible for reducing air pollution (56\% of beans) rather than the local community $(18 \%)$, county government $(18 \%)$ or national government $(8 \%)$. Several participants commented that 'the government doesn't do anything', which may explain why participants thought it best to take matters into their own hands. However, the difference found between these two methods was interesting given they took place in similar outdoor settings and in both cases participants were passers-by.

The song 'Mazingira' and associated music video (see an example still in Fig. 9 and the full music video in Supplementary Information) highlighted government inaction on the topic of reducing air pollution in Mukuru, with lyrics including '...there's no way you care... what services are you providing-yet we pay taxes!'. Omanga et al. (2014) in their study of perceptions of air pollution in rural Kenya also found that residents felt government agencies and other stakeholders did not protect the environment. The Mazingira track highlighted the role individuals can play in reducing air pollution, by including 'smoking in the street' in the lyrics. Calling for both individual behaviour change and changes

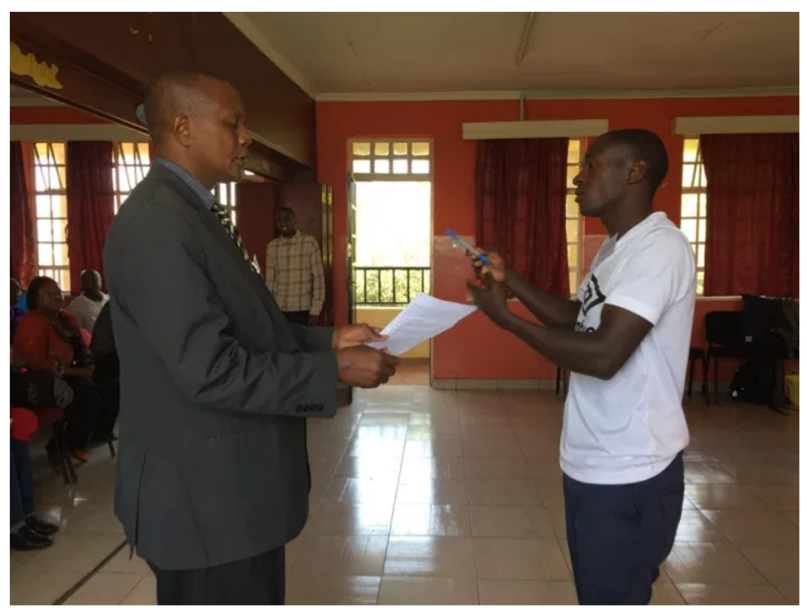

Fig. 10 A policy maker from a local ward (left) takes on the role of a factory worker and attempts to negotiate a better employment contract with the factory owner (right) through legislative theatre. Soon this 'factory worker' was forcibly removed by factory security due to insubordination and the problem remained unresolved.

by those in power here may be in response to the music artists taking part in the AIR Network project from the outset and hearing about findings from the other methods, which fed into the writing of the song and production of the video. Communicating authentic voices through music such as Mazingira can open up spaces for dialogue about environmental issues (Publicover et al., 2018), including on local radio and TV.

Spectactors in the legislative theatre piece suggested possible solutions, and concrete actions and pledges were made by participants in the post-theatre workshop. The first legislative theatre piece focused on occupational exposure to air pollutants while working in the factories bordering Mukuru. In the piece, dust and gases from machinery caused the worker to experience severe respiratory problems. When policy makers were invited onstage to take on the acting role of a factory worker, suggestions to reduce air pollution exposure included employees demanding the provision of protective clothing, better employment contracts and getting the trade union involved (Fig. 10). These potential 
solutions needed to be led by those with power to make the changes. A typical exchange between the 'employee' (policy maker) and the 'factory owner' (community member) was:

Employee: "Well, then I will get the union involved."

Factory owner: "There are many other people waiting for a job, why should I hire someone who will make trouble for me?"

Eventually after many attempts at solutions from the employee, he was sacked. This process highlights for the stakeholders that often things are not as easy to do in practice as they are to suggest (Boal, 2008). A real strength of using the theatre methods was that they enabled ideas for solutions to be challenged in real-time by other participants with divergent views (Salvador, 2014). The second legislative piece theatre focussed on service delivery of firefighting. In this piece, the firefighters arrive to deal with a sudden blaze in a home in Mukuru, but soon run out of water, therefore letting the fire burn longer and creating air pollution, as well as damaging property and risking lives. Again, it was impossible for any individual to make positive changes to the scenario because these sorts of systemic changes to service delivery can only be accomplished by those in power.

Although there were many overlaps in terms of the solutions generated using the various methods (see Fig. 8), there were differences identified, highlighting how the use of multiple methods can help to paint a broader picture (or collage (Freeman, 2020)) of solutions to address problems like air pollution. Further, the solutions proposed addressed the air pollution problems perceived by community members (rather than those problems observed within the community by researchers), meaning the identified solutions were better targeted to addressing the concerns of the community than if generated by the researchers (Chammas et al., 2020).

Creating space for discussion of systemic issues. Our use of multiple methods provided space for discussion of more systemic issues, as while the focus of the project was on air pollution, we often found ourselves exploring much wider social, environmental and economic issues with residents of Mukuru. Tackling these issues holistically could address some underlying issues of urban poverty and urban development. Through sharing power and control over the aims, approaches, and outcomes of this project, we moved away from methodological imperialism, in favour of indigenous and local knowledge and ways of knowing (Chilisa, 2017). For example, the theatre pieces started with air pollution, but ended up exploring the underlying issues facing residents in Mukuru, namely the absence of job opportunities away from local industries, absence of basic water and sanitation services, and the residents' lack of agency (Muindi et al., 2014). These more systemic issues were then discussed in the workshop following the legislative theatre. Workshop participants, including policy-makers and residents, were divided into four groups, each representing one of the key issues that was raised in the piece: lack of labour law enforcement, the need for job creation, fire risk, and lack of infrastructure (and planning) in Mukuru. They generated plans to tackle the issues, for example, there was a suggestion to set up a community-based organisation to provide financing (small start-up loans) to support youth interested in starting a business, to reduce reliance on local factories for jobs. This would have multiple benefits for the individuals involved, including reducing their occupational exposure to air pollution, providing income and improving their sense of agency. Solutions generated from the participatory mapping would have benefits beyond improving air quality, for example, electricity provision to reduce reliance on solid fuels for cooking, job creation for the young people to reduce reliance on local industries for work and road maintenance to reduce road dust resuspension. Our methods supported bottom-up solution generation for problems identified by the community members themselves. This community-level knowledge co-creation is central to building capacity for transformative development outcomes (Ziervogel et al., 2021).

While we, as researchers, came to Mukuru with an interest in exploring experiences of air pollution, for residents, air pollution was just another part of daily life and was inextricably linked to other aspects of their lives. Our narrow focus likely resulted from a combination of the research funding requirements, i.e. the researcher's pursuit of project deliverables and the common inflexibility of research funding (Pohl et al., 2008), and/or reflected the disciplinary silos that researchers often inhabit in academia and which tend to be nurtured by funders (Clasen and Smith, 2019). Ngo et al. (2017) working in another informal settlement in Nairobi, also found that participants in their project did not see air pollution as separate from other environmental issues, such as overflowing sewers. Clasen and Smith (2019) called for much greater integration of those working on $\mathrm{WaSH}$ (water, sanitation and hygiene) and those working on air pollution, as they both affect health, require individual, community and policy action to resolve, and impact the same populations. Indeed, community perceptions of air pollution incorporated issues around drainage, water and toilets, which may not be at the forefront of air pollution scientists' minds. If we are to achieve the SDGs, a much more joined up approach to research and development is needed that considers systems rather than focusing on a system's component parts (Stafford-Smith et al., 2017). Mukuru residents approached the air pollution problem in a more holistic way than the researchers, emphasising the importance of the co-creation approach when aiming for research that delivers real world impact.

Limitations. The main limitation of our study was that by focusing on such a breadth of methods, the depth of analysis undertaken did not always meet the usual disciplinary standards. However, by collating the findings from these various methods, we were able to build a wider understanding of the problems of air pollution faced by Mukuru residents and potential solutions. Co-creation requires researchers to relinquish some control of the project and its expected outcomes, and managing expectations of community members of what can be achieved with the funding available is challenging. There is a significant time input required to undertake this type of research in a meaningful way. Linked to resourcing was our lack of engagement with surrounding industries, building these trusting relationships requires more time than we had available on the project. Working remotely in different time zones was another potential challenge, although we largely mitigated this by communicating via WhatsApp (mainly with community researchers) and email (mainly with academic researchers) between our face to face meetings in Nairobi.

Recommendations for future global challenges research. Transdisciplinary research approaches are vital for tackling the sustainability challenges that the world faces today, including air pollution. Future research in this space should utilise transdisciplinary research approaches, considering carefully the mix of the team, and the methods used.

Creative approaches such as those used in this project are recommended as they offer a broad entry point for discussing environmental issues in a holistic way. They can help bridge scientific and lay knowledge of issues and build a shared language 
for discussing issues. They can help identify the issues of concern and potential actors for solutions, or perceived responsibilities.

Projects should provide opportunities (space and time) for decision-makers at all levels in society and community stakeholders to discuss issues as this can reveal the interconnectedness of problems, for example, air pollution and water and sanitation provision, and to co-create potential solutions. Solutions that arise from these discussions are more likely to be sustainable, effective and culturally appropriate.

\section{Conclusion}

Working in this transdisciplinary co-created way, and utilising a combination of qualitative, participatory and creative methods, allowed us to reveal aspects of air pollution in Mukuru that we would not have identified otherwise. Using these methodological approaches, we gained a more complex, nuanced and holistic understanding of how air pollution is perceived in Mukuru, and created new opportunities for dialogue and critical reflection on the topic of air pollution in the community. Throughout the project, all parties gained new skills in different research methods, and a greater understanding of air pollution. The diverse research and communication methods used allowed us to reach large (and varied) audiences.

As outlined, taking this sort of collaborative and creative approach is not without its difficulties. However, the benefits clearly outweigh the drawbacks and help support the development of strong, long-term partnerships between researchers and the communities in which they are working, which is vital if real and sustainable impact is the ultimate aim. This is particularly important given the collaborative partnerships at all levels (as outlined in SDG17 Global Partnerships for Sustainable Development) required to achieve the SDGs by 2030 . We would urge researchers grappling with similarly complex problems to consider using these approaches in their work.

\section{Data availability}

Interview data generated during the current study are not publicly available as consent was not given for this purpose from interviewees. Other data are included in this published article.

Received: 14 April 2021; Accepted: 2 November 2021; Published online: 19 November 2021

\section{References}

Avis W (2018) Air pollution exposure amongst waste pickers in Dandora Dumpsite. ASAP-East Africa Vulnerability Scoping Study no. 2. University of Birmingham, Birmingham, UK

Avis W, Mariga S, Singh A (2018) Air pollution exposure in low income households in Kampala. ASAP-East Africa Vulnerability Scoping Study no. 6. University of Birmingham, Birmingham, UK

Bates V, Bleakley A, Goodman S (2015) Medicine, health and the arts: approaches to the medical humanities. Routledge, London

Bauman R (1986) Story, performance, and event: contextual studies of oral narrative. Cambridge University Press, Cambridge

Beguy D, Elung'ata P, Mberu B, Oduor C, Wamukoya M, Nganyi B, Ezeh A (2015) Health \& demographic surveillance system profile: The Nairobi Urban Health and Demographic Surveillance System (NUHDSS). Int J Epidemiol 44:462-471. https://doi.org/10.1093/ije/dyu251

Bickerstaff K (2004) Risk perception research: socio-cultural perspectives on the public experience of air pollution. Environ Int https://doi.org/10.1016/ j.envint.2003.12.001

Bickerstaff K, Walker G (2001) Public understandings of air pollution: the "localisation" of environmental risk. Glob Environ Chang 11:133-145. https:// doi.org/10.1016/S0959-3780(00)00063-7

Biggs M, Buchler D (2008) Eight criteria for practice-based research in the creative and cultural industries. Art Design Commun High Educ 7(1):5-18
Bleakley A (2019) The Routledge handbook of medical humanities. Routledge, London

Boal A (2008) Theatre of the oppressed, 3rd edn. Pluto Press

Brooks R, Lainio A, Lažetić P (2020) Using creative methods to research across difference. An introduction to the special issue. Int J Soc Res Methodol 23:1-6. https://doi.org/10.1080/13645579.2019.1672281

Brown G, Kyttä M (2018) Key issues and priorities in participatory mapping: toward integration or increased specialization? Appl Geogr 95:1-8. https:// doi.org/10.1016/j.apgeog.2018.04.002

Brown G, Sanders S, Reed P (2018) Using public participatory mapping to inform general land use planning and zoning. Landsc Urban Plan 177:64-74. https:// doi.org/10.1016/j.landurbplan.2018.04.011

Bruce N, Perez-Padilla R, Albalak R (2000) Indoor air pollution in developing countries: a major environmental and public health challenge. Bull World Health Organ 78:1078-1092. https://doi.org/10.1590/S004296862000000900004

Bruner J (1990) The Jerusalem-Harvard lectures. Acts of meaning. Harvard University Press

Cadag JRD, Gaillard J (2012) Integrating knowledge and actions in disaster risk reduction: the contribution of participatory mapping. Area 44:100-109. https://doi.org/10.1111/j.1475-4762.2011.01065.x

Chambers R (1994) The origins and practice of participatory rural appraisal. World Dev 22:953-969. https://doi.org/10.1016/0305-750X(94)90141-4

Chammas G, Kayed S, Al Shami A, Kays W, Citton M, Kalot M, Al Marj E, Fakhr M, Yehya NA, Talhouk SN, Al-Hindi M, Zein-El-Dine S, Tamim H, Lakkis I, Abou Najm M, Saliba NA (2020) Transdisciplinary interventions for environmental sustainability. Waste Manag 107:159-171. https://doi.org/10.1016/ j.wasman.2020.03.043

Checkley W, Pollard SL, Siddharthan T, Babu GR, Thakur M, Miele CH, van Schayck OC (2016) Managing threats to respiratory health in urban slums. Lancet Respir Med 4(11):852-854. https://doi.org/10.1016/S2213-2600(16) 30245-4

Chilisa B (2017) Decolonising transdisciplinary research approaches: an African perspective for enhancing knowledge integration in sustainability science. Sustain Sci 12:813-827. https://doi.org/10.1007/s11625-017-0461-1

Cinderby S (2010) How to reach the "hard-to-reach": the development of Participatory Geographic Information Systems (P-GIS) for inclusive urban design in UK cities. Area 42:239-251

Cinderby S, de Bruin A, Cambridge H, Muhoza C, Ngabirano A (2021) Transforming urban planning processes and outcomes through creative methods. Ambio 1-17. https://doi.org/10.1007/s13280-020-01436-3

Cinderby S, Forrester J (2005) Facilitating the local governance of air pollution using GIS for participation. Appl Geogr 25:143-158. https://doi.org/10.1016/ j.apgeog.2005.03.003

Cinderby S, Snell C, Forrester J (2008) Participatory GIS and its application in governance: the example of air quality and the implications for noise pollution. Local Environ 13:309-320. https://doi.org/10.1080/ 13549830701803265

Clasen T, Smith KR (2019) Let the "A" in WASH Stand for Air: Integrating Research and Interventions to Improve Household Air Pollution (HAP) and Water, Sanitation and Hygiene (WaSH) in Low-Income Settings. Environ Health Perspect 127:2. https://doi.org/10.1289/EHP4752

Cochrane L, Corbett J (2018) Participatory mapping. In: Servaes J (Ed) Handbook of communication for development and social change. Springer, Singapore

Coemans S, Hannes K (2017) Researchers under the spell of the arts: two decades of using arts-based methods in community-based inquiry with vulnerable populations. Educ Res Rev 22:34-49

Cole T, Carlin N, Carson R (2014) Medical humanities: an introduction. Cambridge University Press, Cambridge

Conticini E, Frediani B, Caro D (2020) Can atmospheric pollution be considered a co-factor in extremely high level of SARS-CoV-2 lethality in Northern Italy? Environ Pollut 261:114465

Commodore A, Wilson S, Muhammad O et al. (2017) Community-based participatory research for the study of air pollution: a review of motivations, approaches, and outcomes. Environ Monit Assess 189:378. https://doi.org/ 10.1007/s10661-017-6063-7

Cook JE, Purdie-Vaughns V, Meyer IH, Busch JTA (2014) Intervening within and across levels: a multilevel approach to stigma and public health. Soc Sci Med 103:101-109. https://doi.org/10.1016/j.socscimed.2013.09.023

Corburn J, Agoe V, Ruiz Asari M, Ortiz J, Patterson R, Ngau P, Mwaura M, Kinya D, Bosibori B, Kang'ethe I, Mohamud A, Jepkosgei M, Wakaba D, Makau J, Weru J, Njoroge P, Kairuki K, Wairitu J, Joseph K, Nyambuga K, Githiri G, Kim H-S, Walthert L, Mutinda MW, Kano M (2017) Situational analysis of Mukuru Kwa Njenga, Kwa Reuben \& Viwandani. Technical Paper

Crawford P, Brown B, Baker C, Tischler V, Abrams B (2015) Health humanities. Palgrave MacMillan, Basingstoke

DeFranco E, Moravec W, Xu F, Hall E, Hossain M, Haynes EN, Muglia L, Chen A (2016) Exposure to airborne particulate matter during pregnancy is 
associated with preterm birth: a population-based cohort study. Environ Health 15. https://doi.org/10.1186/s12940-016-0094-3

deSouza P (2020) Air pollution in Kenya: a review. Air Qual Atmos Health 13:1487-1495. https://doi.org/10.1007/s11869-020-00902-x

Dianati K, Zimmermann N, Milner J, Muindi K, Ezeh A, Chege M, Mberu B, Kyobutungi C, Fletcher H, Wilkinson P, Davies M (2019) Household air pollution in Nairobi's slums: a long-term policy evaluation using participatory system dynamics. Sci Total Environ 660:1108-1134. https://doi.org/ 10.1016/j.scitotenv.2018.12.430

Egondi T, Muindi K, Kyobutungi C, Gatari M, Rocklöv J (2016) Measuring exposure levels of inhalable airborne particles (PM2.5) in two socially deprived areas of Nairobi, Kenya. Environ Res 148:500-506. https://doi.org/ 10.1016/j.envres.2016.03.018

Ezzati M, Kammen DM (2002) The health impacts of exposure to indoor air pollution from solid fuels in developing countries: Knowledge, gaps, and data needs. Environ Health Perspect. https://doi.org/10.1289/ehp.021101057

Finney N, Rishbeth C (2006) Engaging with marginalised groups in public open space research: the potential of collaboration and combined methods. Plan Theory Pract 7:27-46. https://doi.org/10.1080/14649350500497406

Forouzanfar MH et al. (2016) Global, regional, and national comparative risk assessment of 79 behavioural, environmental and occupational, and metabolic risks or clusters of risks, 1990-2015: a systematic analysis for the Global Burden of Disease Study 2015. Lancet 388:1659-1724. https://doi.org/ $10.1016 /$ S0140-6736(16)31679-8

Freeman C (2020) Multiple methods beyond triangulation: collage as a methodological framework in geography. Geogr Ann Ser B 102:328-340. https:// doi.org/10.1080/04353684.2020.1807383

Gauntlett D (2007) Creative explorations. Routledge

Gathogo J (2007) Storytelling as a methodology in developing a theology of reconstruction. Stud Hist Eccles XXXIII(1):155-186

Giannakis E, Kushta J, Bruggeman A, Lelieveld J (2019) Costs and benefits of agricultural ammonia emission abatement options for compliance with European air quality regulations. Environ Sci Eur 31:93. https://doi.org/ 10.1186/s12302-019-0275-0

Gitonga PN, Delport A (2015) Exploring the use of hip hop music in participatory research studies that involve youth. J Youth Stud 18:984-996. https://doi.org/ $10.1080 / 13676261.2015 .1020929$

Gold J (2002) The story species: our life-literature connection. Fitzhenry and Whiteside, Markam

Gottschall J (2012) The storytelling animal: how stories make us human. Houghton Mifflin Harcourt, Boston

Greenhalgh T, Jackson C, Shaw S, Janamian T (2016) Achieving research impact through co-creation in community-based health services: literature review and case study. Milbank Q. https://doi.org/10.1111/1468-0009.12197

Gulis G, Mulumba JAA, Juma O, Kakosova B (2004) Health status of people of slums in Nairobi, Kenya. Environ Res 96:219-227. https://doi.org/10.1016/ j.envres.2004.01.016

Gulyani S, Talukdar D, Bassett EM (2018) A sharing economy? Unpacking demand and living conditions in the urban housing market in Kenya. World Dev 109:57-72. https://doi.org/10.1016/j.worlddev.2018.04.007

Harper J (2004) Breathless in Houston: a political ecology of health approach to understanding environmental health concerns. Med Anthropol Cross Cult Stud Heal Illn. https://doi.org/10.1080/01459740490513521

Hartley J, McWilliam K (2009) Story circle: digital storytelling around the world. Wiley-Blackwell, Chichester

He J, Liu H, Salvo A (2019) Severe air pollution and labor productivity: evidence from industrial towns in China. Am Econ J Appl Econ 11:173-201. https:// doi.org/10.1257/app. 20170286

Henricks TS (2015) Play and the human condition. University of Illinois Press

Hoek G, Krishnan RM, Beelen R, Peters A, Ostro B, Brunekreef B, Kaufman JD (2013) Long-term air pollution exposure and cardio-respiratory mortality: a review. Environ Heal A. https://doi.org/10.1186/1476-069X-12-43

Holgate S, Stokes-Lampard H (2017) Air pollution-a wicked problem. BMJ. https://doi.org/10.1136/bmj.j2814

Ingold T (2007) Earth, sky, wind, and weather. J R Anthropol Inst 13:S19-S38. https://doi.org/10.1111/j.1467-9655.2007.00401.x

Jiang Z, Kobylinska T, The Voice of Domestic Workers (2020) Art with marginalised communities: participatory video as a tool of empowerment and resistance for migrant domestic workers in London. City 24:348-363. https:// doi.org/10.1080/13604813.2020.1739460

Jones P, Evans J (2011) Rescue geography: place making, affect and regeneration. Urban Stud 49:2315-2330. https://doi.org/10.1177/0042098011428177

Jones P, Evans J (2012) The spatial transcript: analysing mobilities through qualitative GIS. Area 44:92-99. https://doi.org/10.1111/j.1475-4762.2011.01058.x

Kleinman A (1987) Explanatory models in health-care relationships: a conceptual frame for research on family-based health-care activities in relation to folk and professional forms of clinical care. In: Stoeckle J (Ed) Encounters between patients and doctors: an anthology. MIT Press, Cambridge and London
KNBS (2020) 2019 Kenya population and housing census, vol I: Population by county and sub-county-Kenya National Bureau of Statistics [WWW Document]. https://www.knbs.or.ke/?wpdmpro=2019-kenya-populationand-housing-census-volume-i-population-by-county-and-sub-county. Accessed 2 Aug 2021.

Lambert J (2002) Digital storytelling: capturing lives, creating community. Digital Diner Press, Berkeley

Lang DJ, Wiek A, Bergmann M, Stauffacher M, Martens P, Moll P, Swilling M, Thomas CJ (2012) Transdisciplinary research in sustainability science: practice, principles, and challenges. Sustain Sci 7:25-43. https://doi.org/ 10.1007/s11625-011-0149-x

Lang DJ, Wiek A, von Wehrden H (2017) Bridging divides in sustainability science. Sustain Sci 12:875-879. https://doi.org/10.1007/s11625-017-0497-2

Langham K (2017) Play as a design tool. In: Poulsen M (Ed.) The power of playvoices from the play community. Colophon, Aarhus, pp. 107-113

Lindhout P, Teunissen T, Visse M (2020) Inarticulate experiences in qualitative health research: bounds and bounty of expression types. Int J Qual Methods. https://doi.org/10.1177/1609406920978107

Mahalanabis D, Gupta S, Paul D, Gupta A, Lahiri M, Khaled MA (2002) Risk factors for pneumonia in infants and young children and the role of solid fuel for cooking: a case-control study. Epidemiol Infect 129:65-71. https://doi.org/ $10.1017 /$ S0950268802006817

Marshall F, Dolley J, Priya R (2018) Transdisciplinary research as transformative space making for sustainability: enhancing propoor transformative agency in Periurban contexts. Ecol Soc 23. https://doi.org/10.5751/ES-10249-230308

Mattingly C, Garro LC (2000) Narrative and the cultural construction of illness and healing. University of California Press

Mberu B, Wamukoya M, Oti S, Kyobutungi C (2015) Trends in causes of adult deaths among the urban poor: evidence from Nairobi urban health and demographic surveillance system, 2003-2012. J Urban Heal 92:422-445. https://doi.org/10.1007/s11524-015-9943-6

McCarron A, Uny I, Caes L, Lucas SE, Semple S, Ardrey J, Price H (2020) Solid fuel users' perceptions of household solid fuel use in low- and middle-income countries: a scoping review. Environ Int 143:105991. https://doi.org/10.1016/ j.envint.2020.105991

Mobarak AM, Dwivedi P, Bailis R, Hildemann L, Miller G (2012) Low demand for nontraditional cookstove technologies. Proc Natl Acad Sci USA 109:10815-10820. https://doi.org/10.1073/pnas.1115571109

Mortimer K, Ndamala CB, Naunje AW, Malava J, Katundu C, Weston W, Havens D, Pope D, Bruce NG, Nyirenda M, Wang D, Crampin A, Grigg J, Balmes J, Gordon SB (2017) A cleaner burning biomass-fuelled cookstove intervention to prevent pneumonia in children under 5 years old in rural Malawi (the Cooking and Pneumonia Study): a cluster randomised controlled trial. Lancet 389:167-175. https://doi.org/10.1016/S0140-6736(16)32507-7

Muindi K, Egondi T, Kimani-Murage E, Rocklov J, Ng N (2014) "We are used to this": a qualitative assessment of the perceptions of and attitudes towards air pollution amongst slum residents in Nairobi. BMC Public Health 14:226. https://doi.org/10.1186/1471-2458-14-226

Muindi K, Kimani-Murage E, Egondi T, Rocklov J, Ng N (2016) Household air pollution: Sources and exposure levels to fine particulate matter in Nairobi slums. Toxics 4. https://doi.org/10.3390/toxics4030012

Muungano wa Wanavijiji (2018) https://www.muungano.net/ Accessed 23 Oct 2021

Nantanda R, Buteme S, va Kampen S, Cartwright L, Pooler J, Barton A, Callaghan L, Mirembe J, Ndeezi G, Tumwine JK, Kirenga B, Jones R (2019) Feasibility and acceptability of a midwife-led health education strategy to reduce exposure to biomass smoke among pregnant women in Uganda, A FRESH AIR project. Glob Public Health 14:1770-1783. https://doi.org/10.1080/ 17441692.2019 .1642931

Ngo NS, Kokoyo S, Klopp J (2017) Why participation matters for air quality studies: risk perceptions, understandings of air pollution and mobilization in a poor neighborhood in Nairobi, Kenya. Public Health 142:177-185. https:// doi.org/10.1016/j.puhe.2015.07.014

Olufemi O, Reeves D (2004) Lifeworld strategies of women who find themselves homeless in South Africa. Plan Theory Pract 5:69-91. https://doi.org/10.1080/ 1464935042000185071

Omanga E, Ulmer L, Berhane Z, Gatati M (2014) Industrial air pollution in rural Kenya: community awareness, risk perception and associations between risk variables. BMC Public Health 14:377, http://www.biomedcentral.com/1471$2458 / 14 / 377$

Goodfellow T, Taylor W (2009) Urban poverty and vulnerability in Kenya: the urgent need for co-ordinated action to reduce urban poverty, Oxfam GB. https://policypractice.oxfam.org/resources/urban-poverty-and-vulnerability-in-kenya-theurgent-need-for-co-ordinated-actio-123932/ Accessed 21 Oct 2021

Pink S (2015) Doing sensory ethnography, 2nd edn. SAGE Publications

Pohl C, Van Kerkhoff L, Hadorn GH, Bammer G (2008) Integration. In: Hadorn GH, Hoffmann-Riem H, Biber-Klemm S, Grossenbacher-Mansuy W, Joye D, Pohl C, Wiesmann U, Zemp E (Eds) Handbook of transdisciplinary research. Springer, Netherlands, pp. 411-424 
Polk M (2015) Transdisciplinary co-production: designing and testing a transdisciplinary research framework for societal problem solving. Futures 65:110-122. https://doi.org/10.1016/j.futures.2014.11.001

Prentki T, Preston S (Eds) (2009) The applied theatre reader. Routledge

Publicover JL, Wright TS, Baur S, Duinker PN (2018) Music as a tool for environmental education and advocacy: artistic perspectives from musicians of the Playlist for the Planet. Environ Educ Res 24(7):925-936. https://doi.org/ $10.1080 / 13504622.2017 .1365356$

Rankin RE (1969) Air pollution control and public apathy. J Air Pollut Control Assoc 19(8):565-569. https://doi.org/10.1080/00022470.1969.10466523

Ritchie H, Roser M (2017) Air Pollution. Published online at OurWorldInData.org. https://ourworldindata.org/air-pollution, accessed $26 \mathrm{Feb} 2021$

Rouse JR (2000) Indoor air pollution: issues for Bangladesh. UK-Water, Engineering and Development Centre (WEDC), Loughborough University. https://www.bioenergylists.org/stovesdoc/Rouse/rouiap.pdf Accessed 13 Oct 2021

Salvador E (2014) Legislative Theatre: art for community conflict resolution. From desires to laws. J Conflictol 5. https://doi.org/10.7238/joc.v5i1.1444

Shupler M et al. (2021) COVID-19 impacts on household energy and food security in a Kenyan Informal Settlement: The need for integrated approaches to the SDGs. Renew Sustain Energy Rev. 144. https://doi.org/10.1016/j.rser.2021.111018

Sibanda S (2004) "You don't get to sing a song when you have nothing to say": Oliver Mtukudzi's music as a vehicle for socio-political commentary. Soc Dyn 30(2):36-63. https://doi.org/10.1080/02533950408628684

Stafford-Smith M, Griggs D, Gaffney O, Ullah F, Reyers B, Kanie N, Stigson B, Shrivastava P, Leach M, O'Connell D (2017) Integration: the key to implementing the Sustainable Development Goals. Sustain Sci 12:911-919. https:// doi.org/10.1007/s11625-016-0383-3

Sumartojo S, Pink S (2018) Atmospheres and the experiential world. theory and methods, 1st edn. Routledge, London

Twigg $\mathrm{M}$ et al. (2017) Investigating the drivers of air pollution and personal exposure within informal settlements in Nairobi, Kenya [poster] In: Air quality-the wider picture. Current issues and new technologies, Royal Society of Chemistry, London, 13-14 December 2017

West SE, Büker P, Ashmore M, Njoroge G, Welden N, Muhoza C, Osano P, Makau J, Njoroge P, Apondo W (2020) Particulate matter pollution in an informal settlement in Nairobi: using citizen science to make the invisible visible. Appl Geogr 114:102133. https://doi.org/10.1016/j.apgeog.2019.102133

Wilson M (2021) Slow storytelling and hybridity: restaging community storytelling as a tool for co-thinking. Book 2.0 11(1):107-123. https://doi.org/10.1386/ btwo_00047_1

WHO (World Health Organisation) (2018a) Ambient (outdoor) air pollution. https://www.who.int/en/news-room/fact-sheets/detail/ambient-(outdoor)air-quality-and-health. Accessed 2 Aug 2021

WHO (World Health Organisation) (2018b) Indoor air pollution and household energy: the forgotten 3 billion. www.who.int/en/news-room/fact-sheets/ detail/household-air-pollution-and-health

Wu X, Nethery RC, Sabath BM, Braun D, Dominici F (2020) Air pollution and Covid-19 mortality in the United States: Strengths and limitations of an ecological regression analysis. Sci Adv. 6(45). https://doi.org/10.1126/ sciadv.abd 4049

Ziervogel G, Enqvist J, Metelerkamp L, van Breda J (2021) Supporting transformative climate adaptation: community-level capacity building and knowledge co-creation in South Africa, Climate Policy. https://doi.org/10.1080/ 14693062.2020 .1863180

\section{Acknowledgements}

This project was funded by the Medical Research Council and the Arts and Humanities Research Council (grant reference AH/R006059/1). The authors wish to thank all those who took part in the AIR Network activities: the community members who led and participated in mini-projects, the community members who led and attended performances, Muungano wa Wanavijiji staff, the researchers and other stakeholders who took part in the inception workshop and policy workshop, and our project advisory group members.

\section{Competing interests}

The authors declare no competing interests.

\section{Ethical approval}

Ethical approval for this project was gained through the multidisciplinary Environment and Geography Ethics Committee at the University of York. All research was conducted within relevant guidelines.

\section{Informed consent}

Informed consent was obtained from all participants.

\section{Additional information}

Supplementary information The online version contains supplementary material available at https://doi.org/10.1057/s41599-021-00969-6.

Correspondence and requests for materials should be addressed to Sarah E. West.

Reprints and permission information is available at http://www.nature.com/reprints

Publisher's note Springer Nature remains neutral with regard to jurisdictional claims in published maps and institutional affiliations.

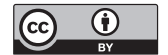

Open Access This article is licensed under a Creative Commons Attribution 4.0 International License, which permits use, sharing, adaptation, distribution and reproduction in any medium or format, as long as you give appropriate credit to the original author(s) and the source, provide a link to the Creative Commons license, and indicate if changes were made. The images or other third party material in this article are included in the article's Creative Commons license, unless indicated otherwise in a credit line to the material. If material is not included in the article's Creative Commons license and your intended use is not permitted by statutory regulation or exceeds the permitted use, you will need to obtain permission directly from the copyright holder. To view a copy of this license, visit http://creativecommons.org/ licenses/by/4.0/.

(C) The Author(s) 2021 